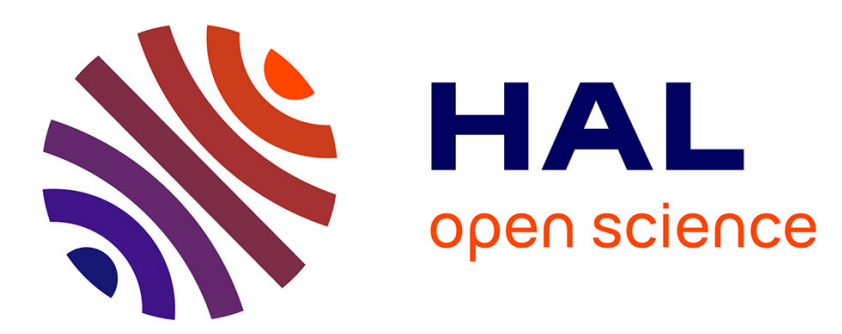

\title{
Interpretation of shallow electromagnetic instruments resistivity and magnetic susceptibility measurements using rapid $1 \mathrm{D} / 3 \mathrm{D}$ inversion
}

Christophe Benech, Michel Dabas, François Xavier Simon, Alain Tabbagh, Julien Thiesson

\section{To cite this version:}

Christophe Benech, Michel Dabas, François Xavier Simon, Alain Tabbagh, Julien Thiesson. Interpretation of shallow electromagnetic instruments resistivity and magnetic susceptibility measurements using rapid 1D/3D inversion. Geophysics, 2016, 81 (2), pp.E103-E112. 10.1190/geo2014-0549.1 . hal-01375877

\section{HAL Id: hal-01375877 \\ https://hal.science/hal-01375877}

Submitted on 5 Oct 2016

HAL is a multi-disciplinary open access archive for the deposit and dissemination of scientific research documents, whether they are published or not. The documents may come from teaching and research institutions in France or abroad, or from public or private research centers.
L'archive ouverte pluridisciplinaire HAL, est destinée au dépôt et à la diffusion de documents scientifiques de niveau recherche, publiés ou non, émanant des établissements d'enseignement et de recherche français ou étrangers, des laboratoires publics ou privés. 
1 Interpretation of shallow EMI resistivity and magnetic susceptibility measurements using rapid 1D/3D inversion

3

4 Short title: Rapid1D/3D inversion of shallow EMI

5 Authors: Christophe Benech ${ }^{1}$, Michel Dabas ${ }^{2}$, François-Xavier Simon ${ }^{3}$, Alain Tabbagh ${ }^{4}$, 6 Julien Thiesson ${ }^{4}$

7

8

${ }^{1}$ UMR 5133 Archéorient, Maison de l'Orient et de la Méditerranée - Université Lyon 2 F-69365 Lyon

${ }^{2}$ Geocarta, 5 rue de la banque F-75002 Paris

${ }^{3}$ USR3550, MSH, 4 rue Ledru, F-63000, Clermont-Ferrand

${ }^{4}$ Sorbonne Universités, UPMC Paris6, UMR7619, Métis, F-75252 Paris

Corresponding author: Alain Tabbagh, alain.tabbagh@upmc.fr

\section{Abstract}

This paper proposes an inversion process of EMI data based on a two-step approach with 1D inversion of the entire studied surface and a fast 3D inversion applied over limited areas. This process is similar to that formerly used in resistivity prospection. For the study of soil (environmental, engineering or archaeological explorations) low frequency electromagnetic instruments (referred to as Slingram EMI, or EMI) have highly useful specificities. They are light, easy to move in the field, and can simultaneously measure the ground's electrical conductivity and magnetic susceptibility; they have thus been used to map these properties over large surface areas, within relatively short periods of time and at reasonable expense. The possibility of combining several coil geometries has opened up the potential for multi-depth techniques and systematic 1D inversion, which are found to be sufficiently revealing to allow larger portions of surveyed areas to be analysed. 
In the 'targeted areas' selected for 3D inversion, the geometries of the 3D features and the resistivity and/or susceptibility contrasts are determined. This step is based on the method of moments where only 3D heterogeneities are meshed, and only a small number of major characteristics, such as contrast, thickness, width, etc., are searched for. This process was first applied to synthetic data, then to data acquired at an experimental test site, and finally to field cases. The rapid 3D inversion complements the $1 \mathrm{D}$ one by solving a series of issues: correction for the apparent anisotropy generated by the instrument configuration, multi-arched anomalies, precise location of lateral changes and determination of the properties contrasts. The inversion results highlight the importance of the instrument geometry. It is also shown that apparent magnetic susceptibility data can be more appropriate for the determination of the volume of man-made features, and is highly complementary to conductivity data.

\section{Key words}

Soil resistivity and magnetic susceptibility, multi-depth EMI prospection, 1D and 3D successive inversions, archaeological prospection

\section{Introduction}

The application of Slingram electromagnetic induction (EMI) devices to near-surface studies began during the 1960s in archaeological prospection. The data initially gave rise to a series of interpretation difficulties, due to the unexpected influence of the ground's magnetic susceptibility in the measured responses (Scollar et al. 1990). It was later recognized that an appropriate choice of coil separation and frequency could allow the conductivity response to be distinguished from that of the magnetic susceptibility (Tite and Mullins, 1970): in cases where the so-called induction number is sufficiently low, the magnetic susceptibility generates an in-phase response while the electrical conductivity a quadrature out of phase one. 
The attractive benefits of this technique have led to considerable research, in an effort to assess its potential advantages and drawbacks with respect to those of the previously implemented, conventional magnetic field and DC resistivity techniques. The design of a new family of EM instruments by Geonics Ltd (Canada) (McNeil 1980) led to large applications in soil salinity mapping (De Jong et al. 1979), which were then extended to the study of other soils (Kachanoski et al. 1988).

Conductivity measurements are straightforward with an EMI instrument, since it can be more easily deployed and operated in the field than a DC resistivity array. EMI instruments have thus experienced considerable developments, for rapid near-surface mapping applications over extended areas (Bendjoudi et al. 2002, Vitharana et al. 2008, Hoefer et al. 2010). Similarly to the case of airborne electromagnetic measurements (AEM) prospectors have to face with the complexity of interpreting huge volumes of $3 \mathrm{D}$ data (see for example Huang and Fraser, 1996). The first interpretations involved the application of a 1D point-bypoint inversion, after having outlined the conditions under which this interpretation is relevant (Guérin et al. 1996). Later, the development of 1D modelling included magnetic susceptibility and dielectric permittivity in the analysis of EMI data (Huang and Fraser 2002, Farquharson et al. 2003). Similarly to the case of galvanic resistivity, more sophisticated laterallyconstrained 1D inversions have been applied (Santos 2004, Auken and Christiansen 2004) or joint inversion has been used with other techniques, magnetic cartography in particular (Benech et al. 2002).

Nowadays, new ground-based multi-coil devices (Saey et al. 2012, Bonsall et al. 2013) give access to precise multi-depth data, while ensuring accurate collocation of the data fields. This stimulates the need of inversion procedures that fully exploit the advantages of these instruments, in terms of imaging both conductivity and susceptibility of subsurface features. One also wants to take into account the need of a rapid method usable on a laptop allowing 
easily reconsidering the starting parameters and the extent of the considered area. Compared with other EM techniques one must note that both the transmitter(s) and the receiver(s) are moving thus (i) the considered calculations are significantly longer than for fixed sources EM because the primary field needs to be calculated for each location of the transmitter, but (ii) in the surveyed field the electromagnetic coupling is negligible between 3D heterogeneities separated by too great distances (several times the inter-coil separation(s)). To overcome the difficulties and taking into consideration the practical conditions associated with 3D inversion, a two-steps efficient approach has been proposed for the processing of multi-depth DC resistivity data (Brinon et al. 2012). The first step involves defining the 1D structure of the subsurface. Then the interpreter defines a 'targeted area', which is a limited area surrounding the target(s) of interest and whose surface is several times larger than the range of investigation of the instruments used. The 3D bodies imbedded in the layered terrain are characterized by a limited number of parameters: contrast, thickness, width, length, orientation. This approach is well matched to the characteristics of man-made features that are searched for in archaeological prospection, or in polluted sites exploration. It is straightforwardly implemented when using the moment method (MoM) for forward modelling. MoM combines analytical and numerical calculations, for which only 3D heterogeneities located in a layered 1D terrain need to be meshed. Its application in EM is less simple than in DC resistivity but both the conductivity and susceptibility contrasts can be taken into account (Tabbagh 1985).

In the present paper this approach is applied to EMI survey data in order to evaluate its potential. One first defines the successive steps of the inversion process before inverting synthetic data, data collected above artificial features on a field test site and finally field data collected over archaeological sites. 


\section{Inversion process}

\section{Forward modelling}

The moment method (MoM) has been applied for more than thirty years in EM prospection modelling (Raiche 1974, Hohmann 1975, Tabbagh 1985). 3D bodies located in layered terrain are replaced by an equivalent set of EM dipoles sources. Consequently it allows meshing to be restricted to heterogeneous bodies, but requires an initial 1D layered model and analytical calculations of the fields generated by dipole sources in the layered terrain. These can now be performed very rapidly through the use of convolution calculations to determine the required Hankel transforms (Guptasarma and Singh, 1997). After having determined the 1D surrounding model, the heterogeneous body(ies) imbedded in the layers is (are) meshed, and the intensity of the equivalent secondary sources is determined using a volume integral equation. These sources are then used to compute the resulting secondary field at the surface.

\section{Inversion}

The aim of an inversion process is to determine the unknown quantities representing physical properties of interest. In the present case, these correspond to the electrical resistivity and magnetic susceptibility values, and the geometrical boundaries of selected layer(s) and body(ies). The inversion is achieved by starting with an a priori set of values, representing each of the different inversion parameters, and then iteratively modifying these in order to achieve a sufficiently good fit between the results of the forward model and the experimental data. The Levenberg-Marquardt algorithm (Marquardt, 1963) is used to achieve a linearized iterative process, in which the cost function includes both the Euclidian distance (L2 norm) between the model results and the data, as well as the intensities of the model parameter increments, multiplied by a damping factor the weight of which is reduced during the course of the iterative process. 
In the present case the total inversion process thus follows two steps. The first of these determines, over the entire studied area, an optimised 1D structure that is fitted (point by point, or with a lateral constraint) to the apparent resistivities and susceptibilities measured by the various instruments. In this step, if vertical electrical sounding results are not available, one generally fixes the number of layers at 3 and chooses the a priori resistivity and thickness values by considering the apparent resistivity and magnetic susceptibility values as well as the depth of investigation of each EMI configuration used.

The algorithm is the following. We called $\mathbf{m}$ the vector of the parameters, $\mathbf{m}_{\mathbf{0}}$ the corresponding a priori starting values, $\mathbf{d}$ the vector of the data and $\mathbf{G}$ the operator of the forward calculation. As the problem is non-linear, it is iteratively solved by calculating at iteration, $i, \mathbf{G}$ and its Jacobian $\mathbf{J}$ using $\mathbf{m}_{\mathbf{i}-\mathbf{1}}$ parameters and then deducing the increment $\Delta \mathbf{m}=\mathbf{m}-\mathbf{m}_{\mathbf{i}-\mathbf{1}}$ by derivation of the cost function:

$$
S=\Delta p^{T} \Delta p+\lambda \Delta m^{T} \Delta m
$$

Where

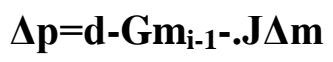

The solved equation is thus:

$$
\left.\mathbf{J}^{\mathbf{T}} \mathbf{J}+\lambda \mathbf{I}\right) \Delta \mathbf{m}=\mathbf{J}^{\mathbf{T}} \Delta \mathbf{p}
$$

Where $\mathbf{I}$ is the identity matrix and $\lambda$ the regularisation parameter. $\lambda$ has a starting value equal to the double of the trace of the $\mathbf{J}^{\mathbf{T}} \mathbf{J}$ matrix divided by the number of parameters and, after, is divided at each iteration $i$ by $i^{1.5}$. The number of iteration depends on the $\mathbf{m}_{\mathbf{0}}$ choice but remains lower than 10 .

Where a $3 \mathrm{D}$ approach is required, the second step begins by defining, over the 'targeted area' surrounding the body(ies), the 1D reference or 'background' model. We adopt the statistic mode of each value of the layer's parameters in that area. Then the parameters 
characterising the 3D heterogeneous body(ies) are determined. The a priori starting values of the horizontal limits the body(ies) are defined by considering the full width half maximum of the anomaly, that of the resistivity by dividing by two the background resistivity if the body is more conductive and by multiplying by two the background resistivity is the body is more resistive. To verify the influence of these a priori values they can also be freely fixed by the interpreter. In 3D inversion the starting value of regularisation parameter, $\lambda$, equals the fifth of the trace of the matrix divided by the number of parameters. The susceptibility contrast is linearly inversed.

The electrical resistivity and magnetic susceptibility are nevertheless two independent properties, but whereas the resistivity distribution modifies the 'primary' field distribution seen by the magnetic grains inside the layered terrain (which could be significantly different from the free space distribution), the susceptibility (and the susceptibility contrast) is sufficiently small for its influence on the primary field to be considered as negligible (Tabbagh 1985). This means that the resistivity distribution must be known before the susceptibility distribution can be inverted, whereas the converse does not apply. In both the 1D and 3D inversion steps, we thus proceed by initially inverting the resistivity distribution and the geometrical limits, before searching for the susceptibility distribution.

\section{Tests of rapid 1D/3D inversion on synthetic data}

Although the 1D inversion of apparent resistivity data maps is well known and has been used and published for more than twenty years (Guérin et al. 1996), the 3D inversion of data raises new issues. The first difficulty, of major importance for the prospector, is to assess the optimal number of independent in-phase and quadrature out of phase measurement maps needed to determine the required resistivity and susceptibility contrasts as well as the geometrical parameters of the body(ies). Although this problem is complex and probably has 
no general solution, the analysis of a synthetic example can contribute to an improved understanding of this process.

We consider a 3D elongated body $3 \mathrm{~m}$ in length, $1 \mathrm{~m}$ in width and $1 \mathrm{~m}$ in thickness (which could correspond to a ditch) embedded in the second layer of a three-layer ground having a resistivity of $20 \Omega \mathrm{m}\left(50 \mathrm{mSm}^{-1}\right.$ conductivity) and a susceptibility of $80 \times 10^{-5} \mathrm{SI}$. The top of the body is located $0.3 \mathrm{~m}$ below the ground. The first layer (corresponding to the topsoil) has a resistivity of $100 \Omega \mathrm{m}\left(10 \mathrm{mSm}^{-1}\right)$, a susceptibility of $30 \times 10^{-5} \mathrm{SI}$, and a thickness equal to $0.2 \mathrm{~m}$. The second layer is characterised by the same parameters with the values: $200 \Omega \mathrm{m}\left(5 \mathrm{mSm}^{-1}\right), 20 \times 10^{-5} \mathrm{SI}$ and $2 \mathrm{~m}$, and the third layer is characterised by the values: $50 \Omega \mathrm{m}\left(20 \mathrm{mSm}^{-1}\right)$ and $10 \times 10^{-5} \mathrm{SI}$. The synthetic data are calculated for three different Slingram EMI devices: a) a $0.6 \mathrm{~m}$ coil separation with HCP (horizontal coplanar) and VCP (vertical coplanar) coil configurations, an operating frequency equal to $27.96 \mathrm{kHz}$, and measurements recorded at $0.08 \mathrm{~m}$ above the ground; b) a $1.0 \mathrm{~m}$ coil separation with HCP and VCP coil configurations, an operating frequency equal to $14.6 \mathrm{kHz}$, and measurements recorded at $0.08 \mathrm{~m}$ above the ground; c) a $1.5 \mathrm{~m}$ separation with a PERP (perpendicular) coil configuration, an operating frequency equal to $8 \mathrm{kHz}$, and measurements recorded $0.15 \mathrm{~m}$ above the ground. We thus have ten independent data sets, of which five correspond to inphase measurements expressed by apparent susceptibility values (Figure 1b) and five correspond to quadrature measurements expressed by apparent resistivity values (Figure 1a), calculated with a fine $0.25 \times 0.25 \mathrm{~m}^{2}$ mesh over a $8 \times 8 \mathrm{~m}^{2}$ surface area, corresponding to a total of 1089 measurement points.

\section{$1 D$ inversion results}

Here the inversion bears over one single unknown parameter, the resistivity (respectively susceptibility of the second layer) in order to be able to compare the results of the different configurations. As expected from theory (Tabbagh 1986), for the apparent 
resistivity measurements $\mathrm{VCP}$ configurations give the best results, with a full width half maximum corresponding to the width of the body, and a minimum reaching $60 \Omega \mathrm{m}(16.7$ $\left.\mathrm{mSm}^{-1}\right)$ for a $1 \mathrm{~m} \mathrm{VCP}$, whereas the latter parameter is determined as $100 \Omega \mathrm{m}\left(10 \mathrm{mSm}^{-1}\right)$ for a $1 \mathrm{~m}$ HCP configuration, and $97 \Omega \mathrm{m}\left(10.3 \mathrm{mSm}^{-1}\right)$ for the PERP $1.5 \mathrm{~m}$ instrument. When the five sets of data are inverted together, the resulting image is less informative than when the VCP configuration is used alone, and the resistivity minimum is determined to be $84 \Omega \mathrm{m}$ $\left(11.9 \mathrm{mSm}^{-1}\right)$. It can thus be understood that it is not necessarily relevant to use several datasets due to its unavoidable 'averaging' effect. However, the difference between the 1D results and the resistivity of the body (20 $\Omega \mathrm{m})$ always remains high.

The 1D inversion of apparent susceptibility datasets produces similar results, except that, as in the apparent susceptibility maps (Figure 1b), the shapes of the anomalies fit the shape of the body more accurately. Similarly to the case of the resistivity, the VCP configuration produces the best result: the VCP $1 \mathrm{~m}$ thus leads to a $55 \times 10^{-5}$ SI maximum, whereas the HCP $1 \mathrm{~m}$ leads to $45 \times 10^{-5} \mathrm{SI}$, the PERP gives $52 \times 10^{-5} \mathrm{SI}$ and all five datasets also find $52 \times 10^{-5} \mathrm{SI}$ for the predefined $80 \times 10^{-5}$ SI susceptibility of the body.

\section{$3 D$ inversion results}

Using the full width half maxima, it is relatively straightforward to determine the shape of the body in the horizontal plane. In the following, we focus on assessing the suitability of various instrument geometries/configurations for the determination of three parameters: the body's vertical extent, its resistivity/conductivity contrast, and its susceptibility contrast. The vertical extent of a body is known to be the most difficult parameter to asses, using the DC resistivity method. The inversion is based on the data corresponding to a small area, i.e. the selected targeted area comprising $5 \times 21$ measurement points centred on the body (thus a $1 \times 5 \mathrm{~m}^{2}$ area, Figures1a and $1 \mathrm{~b}$ ). The results obtained with each dataset (corresponding to 5 different instrumental configurations), and with the 
combined datasets, are presented in Table 1. These include results based on both apparent resistivity measurements, and apparent susceptibility measurements. It can be seen that the computed results are close to the real values (provided in the first line of this table), with the exception of the vertical extent of the body, determined by inverting the apparent resistivity data, which has uncertainties as high as $20 \%$. The most accurate results, obtained using the apparent susceptibility data, can be explained by the stronger geometrical correspondence between the shape of the anomaly and the shape of the causative body. In this example, the VCP $1 \mathrm{~m}$ configuration appears to produce the best inversion results. The most inaccurate resistivity inversion is determined with the PERP instrument (probably as a result of its greater $1.5 \mathrm{~m}$ inter-coil separation), and the most inaccurate susceptibility inversion is determined with the HCP (probably because it has the smallest anomaly). It is important to note that this conclusion is valid even in the case of the smallest inter-coil separation, in agreement with previously published experimental results (Thiesson et al. 2009). Again there is no clear advantage in using the five data sets together, two of the one data sets giving better results.

\section{Field test over an artificial feature}

A field test over artificial features has several advantages when compared to (physical or numerical) modelling: 1) it makes use of real in-field measurements, associated with the usual errors arising from uncertainties in measurement locations, external sources of EM noise, etc., 2) even when the anomalous bodies are built very carefully, the homogeneity of the filling material is never perfect, thus leading to real variability in the body properties, 3) the surrounding medium may also be inhomogeneous, and be characterised by significant natural changes in the immediate vicinity of the body. 

consists of a dual-branch ditch, dug into a silty superficial weathered formation above the Jurassic limestone: the two branches have respectively N-S and E-W alignments, and both have the same dimensions: a $0.8 \times 0.8 \mathrm{~m}^{2}$ section, and a length of $8 \mathrm{~m}$. The ditch is filled with exogenous topsoil, and thus has a higher magnetic susceptibility than the surrounding soil. Its resistivity contrast is low. EMI measurements were carried out in 1999 (Benech 2000), using three different devices: the MS2B magnetic susceptibility probe (Bartington, Ltd), the EM38 (Geonics ltd), which can in principle be used in both VCP and HCP configurations, and the SH3 (a laboratory prototype, (Parchas and Tabbagh 1978)). The MS2 has a 0.18m diameter coincident loop and thus a small depth of investigation, equal to approximately $0.1 \mathrm{~m}$, allowing the susceptibility determination to be restricted to the topsoil. The EM38 has a 1m coil separation and is operated at $14.6 \mathrm{kHz}$. The SH3 has a PARA coil orientation (the two coils have parallel axes at $35^{\circ}$ from vertical so that their direct coupling is null in free space), a $1.5 \mathrm{~m}$ coil separation, and is operated at $8.04 \mathrm{kHz}$. The dimensions of the studied area were 20x20 $\mathrm{m}^{2}$, and this was surveyed using a $1 \times 1 \mathrm{~m}^{2}$ measurement mesh. This mesh was however too coarse to allow changes in sign of the anomaly measured with the EM38 HCP configuration to be correctly monitored. All HCP data was thus excluded from the interpretation process. The measurements were carried out along North-South profiles, with the EM38 and SH3 being aligned with this profile (the line joining the transmitter to the receiver was parallel to the profile).

The three apparent magnetic susceptibility maps shown in Figure 2, and the two apparent resistivity maps shown in Figure 3, were processed by median filtering over a 3x3 points moving window. Even for the topsoil, the two branches of the ditch exhibit a greater magnetic susceptibility than the surrounding terrain, and the global shape of the feature can be recognized. In the apparent resistivity maps, the presence of the ditch is less well defined; it 
appears to be slightly more resistive than the surrounding layer, and is clearly visible on the EM38-VCP map. However, the SH3 map reveals the natural variations of the medium, rather than those of the feature. This can be explained by the greater depth of investigation of this instrument. The apparent anisotropy effect associated (Guérin et al. 1996) with the configuration and orientation of the EM38-VCP may also have affected the measurements.

\section{$1 D$ inversion results}

In accordance with the electrical sounding carried out in the area nearby, the data were inverted by considering a three-layer ground comprising: a topsoil layer with $70 \Omega \mathrm{m}$

resistivity (14.3 $\mathrm{mSm}^{-1}$ conductivity), variable magnetic susceptibility, and $0.15 \mathrm{~m}$ thickness; a second layer having a variable resistivity and magnetic susceptibility and $1 \mathrm{~m}$ thickness; and a third layer, the sound limestone, having a resistivity of $300 \Omega \mathrm{m}\left(3.33 \mathrm{mSm}^{-1}\right)$ and a magnetic susceptibility of $2010^{-5} \mathrm{SI}$. The resistivity of the second layer, $\rho_{2}$, was first inverted using EM38-VCP and SH3 apparent resistivity data. Then, the topsoil and second layer magnetic susceptibilities, $\kappa_{p 1}$ and $\kappa_{p 2}$, were inverted using the MS2B, EM38-VCP and SH3 apparent magnetic susceptibility data. The resulting maps are shown in Figures 2 and 3. As could be expected from the apparent resistivity maps, the exact shape of the ditch cannot be discerned on the $\rho_{2}$ map (Figure 2), but both branches appear to be more resistive, with apparent resistivity values reaching $100 \Omega \mathrm{m}\left(10 \mathrm{mSm}^{-1}\right)$. As expected, in view of the instrument's shallow depth of investigation, the $\kappa_{p 1}$ map reproduces the MS2B map in shape and magnitude. The $\kappa_{p 2}$ map confirms the presence of a zone of significant magnetic contrast below the topsoil layer. All of the results reveal the inhomogeneity of both the material filled into the ditch, and the natural surrounding medium.

\section{$3 D$ inversion results}

The data inversion was applied over two small, separate targeted areas that are delineated by dotted rectangles in Figures 2 and 3. The values of contrast between the two 
branches and the surrounding terrain, determined in terms of conductivity and magnetic susceptibility, are summarized in Table 2.

When the data produced by the EM38-VCP and SH3 instruments are used in the inversion, a conductivity contrast close to $-10 \mathrm{mSm}^{-1}$ is obtained, corresponding to an absolute resistivity of $100 \Omega \mathrm{m}\left(10 \mathrm{mSm}^{-1}\right)$ for the ditch filling material, as opposed to about $50 \Omega \mathrm{m}$ $\left(20 \mathrm{mSm}^{-1}\right)$ for the surrounding terrain. The computation time took $29 \mathrm{mn}$ for the NS branch and $32 \mathrm{mn}$ for the EW one with a 4Go RAM and $2.5 \mathrm{GHz}$ laptop computer.

When the inversion results are considered for each instrument separately, the contrasts are very different: as could be expected from the apparent resistivity maps, the EM38-VCP maps are comparable for the two branches and are characterised by a negative contrast (the feature is less conductive); conversely, with the $\mathrm{SH} 3$ the contrast is positive (the feature looks more conductive) but null and very low, and in fact the ditch is not detected. Thus, SH3 measurements do not contribute to the results of the two-instrument $3 \mathrm{D}$ inversion, which is totally dominated by the data from the EM38-VCP.

When the magnetic susceptibility is considered, the values obtained for both branches reveal a generally stronger magnetic feature. The absolute value of the ditch fill material lies between 50 and $150 \times 10^{-5}$ SI. Again, the results obtained with the EM38-VCP and SH3 instruments are significantly different in magnitude: with the EM38-VCP, the values of contrast determined for the two branches are quite similar, whereas with the SH3 clearly different results are found, approximately $40 \times 10^{-5} \mathrm{SI}$ for the N-S branch, and approximately $110 \times 10^{-5} \mathrm{SI}$ for the E-W branch. This difference remains difficult to explain, because the anisotropy associated with the direction of the applied magnetic field is normally taken into account in the 3D inversion process.

Globally, the experiment conducted over these artificial ditches shows that the inversion results obtained with different instruments can be significantly different, and that 
the coil configuration plays an important role in EMI instrument responses. In conclusion, it can be judicious to use several instrumental configurations when the depths of anomalous features are not known.

\section{Field tests over two archaeological sites}

\section{Gallo-roman site of Vieil-Evreux (Eure, France)}

The test was carried out in the fanum area of this site, called Gisacum during the Roman era. This is a religious centre, located $7 \mathrm{~km}$ east of the capital city of Aulerques Eburovices (now Evreux in Normandy) (Guyard and Lepert 1999). Several new surveying techniques and different devices (Flageul et al. 2013) have already been tested in this area, such that a series of control data was available. The soil resistivity was mapped using a threedepth multipole array ARPC (Automatic Resistivity Profiling) so that both the pattern of the different features and the resistivity ranges of the different materials are known. The site is located in the geological context of a flint-clay plateau, resulting from the weathering of the cretaceous chalk. Above this clay, which has a resistivity of approximately $15 \Omega \mathrm{m}$, the archaeological remains have a variable thickness and can exceed $100 \Omega$.m in resistivity. In the fanum area, the thickness of the archaeological layer is approximately $90 \mathrm{~cm}$. The tests were carried out using the DualEM 421S instrument, a multi-receiver EMI (DualEM sensor manual 2010) operated at $9 \mathrm{kHz}$. It associates one horizontal transmitter loop with three pairs of receivers. In each pair, the first receiver is horizontal, allowing HCP measurements to be made. By rotating the entire apparatus, VCP configuration measurements can be made. The second receiver of each pair is oriented in a radial direction from the transmitter, allowing PERP configuration measurements to be used. The receivers of the first pair are located at respectively $1 \mathrm{~m}$ and $1.1 \mathrm{~m}$ from the transmitter, those of the second pair at $2 \mathrm{~m}$ and $2.1 \mathrm{~m}$, and those of the third pair at $4 \mathrm{~m}$ and $4.1 \mathrm{~m}$. However, in the present test data from the third pair 
were not considered, and only HCP 1m, HCP 2m, PERP $1.1 \mathrm{~m}$ and PERP $2.1 \mathrm{~m}$ data was used for the $1 \mathrm{D} / 3 \mathrm{D}$ inversion. The data was acquired at a high sampling rate, by towing the instrument (with a quad bike) $0.1 \mathrm{~m}$ above the ground. Each data point was located using a dGPS system, thus allowing the resulting map to be produced on a fine, $0.3 \times 0.3 \mathrm{~m}^{2}$ mesh. The apparent resistivity maps obtained with the four configurations are shown in Fig. 4. The approximately $10 \mathrm{~m} \times 10 \mathrm{~m}$ square cella can be seen at the centre of each of these images, and on the east and west sides the external walls of the fanum. The global apparent resistivity is found to have lower values with the PERP $2.1 \mathrm{~m}$ and HCP $2 \mathrm{~m}$ instrument configurations, than for shorter coil separations. This is due to the greater influence of the underlying flint-clay layer. In both HCP images, the anomalies generated by walls correspond to three parallel, resistive/conductive/resistive strips; this experimental result is in full agreement with the theory (Tabbagh 1986), and was achieved thanks to the fine mesh used for this survey. However, such anomalies with this coil configuration can lead to misinterpretation, if the experimental results are not compared with the theoretical model. The wall anomalies are more pronounced on the PERP $1.1 \mathrm{~m}$ map than on the HCP $1 \mathrm{~m}$ map, and the ability of the former to image the wall pattern appears to be equivalent to that of the electrical method (Dabas et al. 2015).

The 3D interpretation allows these different points to be more thoroughly investigated. To this aim, a limited $4.8 \times 3.6 \mathrm{~m}^{2}$ targeted area was defined, including the external wall , which is delineated by a rectangle in Fig. 5 (the cella itself appears to be more complicated, it probably has deeper underground sub-structures). In this zone, 3D interpretation of the electrical data acquired with the ARP@ indicates that the wall has a section of $1.00 \times 0.88 \mathrm{~m}^{2}$ and a resistivity of $70.7 \Omega \mathrm{m}\left(14.1 \mathrm{mSm}^{-1}\right)$, which is in contrast with the second, surrounding layer with a resistivity of $32 \Omega \mathrm{m}\left(31.2 \mathrm{mSm}^{-1}\right)$. The conductivity contrast characterizing the wall is thus $-17.1 \mathrm{mSm}^{-1}$. Table 3 presents the conductivity contrast between the wall and 
surrounding layer, computed using the same geometrical parameters (to define the wall's location and section), based on the data provided by each configuration alone, and on the combined data from all four configurations. In all cases, the contrast is found to be lower than that obtained with DC resistivity measurements. The conductivity contrast determined with the combined data is not greater than the contrast computed from the data produced by each individual instrument. The two configurations giving a qualitatively correct contrast, i.e. PERP $1.1 \mathrm{~m}$ and HCP $2 \mathrm{~m}$, are those which also produce the clearest apparent resistivity maps. The near absence of contrast obtained with the PERP2 configuration, with no detection of the wall, can be explained by the depth of investigation of this configuration. The sign inversion obtained with the HCP $1 \mathrm{~m}$ is a consequence of the three arched anomalies, and confirms that the use of a HCP configuration can lead to considerable interpretation difficulties in the case of small resistive features. These observations again emphasize the advantage and drawback associated with the simultaneous use of several configurations.

\section{Neolithic enclosure at Balloy (Seine et Marne, France)}

The study of this middle Neolithic enclosure provides an interesting example of the usefulness of 3D inversion. The eastern section of this 'Passy' type of funeral enclosure (Mordant 1997) has been the object of multi-method tests. This enclosure was detected by both electrical (square array of $1 \mathrm{~m}$ side) and $\mathrm{SH} 3$ prospection, but not by magnetic prospection using a fluxgate gradiometer with 1nT sensitivity (Hesse 1987) and it is important to explain this failure. The apparent magnetic susceptibility map of this enclosure is shown in Fig. 5. On this site, the cultivated topsoil layer has a susceptibility of $100 \times 10^{-5} \mathrm{SI}$, a resistivity of $70 \Omega \mathrm{m}$ and a thickness of $0.25 \mathrm{~m}$. This layer covers a highly resistive gravel formation (300 $\Omega \mathrm{m})$ with a low susceptibility, equal to $20 \times 10^{-5} \mathrm{SI}$.

3D interpretation was applied to a targeted area in which the ditch can be clearly distinguished (see contours in Figure 5). It shows that the ditch fill material, which contrasts 
with the gravel, is thin, i.e. has a section of $1.4 \times 0.4 \mathrm{~m}^{2}$, and has a relatively low magnetic susceptibility of $51 \times 10^{-5}$ SI. Using these parameters, the magnetic anomaly determined with a fluxgate vertical gradient is not more than $0.5 \mathrm{nT} / \mathrm{m}$. Both the limited thickness and the limited contrast explain why no magnetic anomaly was observed, even with the addition of viscous magnetic remanent magnetization, and confirm the usefulness of EM susceptibility measurements over thin features.

\section{Conclusion}

1D interpretation allows underground structures to be more clearly delineated, and permits a better assessment of variations in the soil's physical properties than simple mapping of apparent properties. The complementary 3D inversion allows solving a series of issues: correction for the apparent anisotropy generated by the instrument configuration, multi-arched anomalies, precise location of lateral changes and determination of the contrasts between the considered body and its surrounding medium.

When applied to EMI data, the rapid 1D/3D inversion process we have proposed not only allows an (expected) improvement in interpretation to be achieved, but also emphasizes the importance of the instrument's geometry, which should be optimally matched with the objectives of the survey. This inversion process is shown to be useful for the assessment of multi-configuration instrument capabilities. In particular, it confirms the difficulties encountered with the use of an HCP configuration, and the conclusions of early theoretical studies of this technique.

Since the analytical and numerical (MoM) calculation method presented in this study is the same as the one already used with the DC resistivity technique, $1 \mathrm{D} / 3 \mathrm{D}$ inversion will offer the possibility of combining DC and EMI data in a joint inversion. This would be useful 
423 to surveyors because EMI is faster for in-field mapping, while DC is more reliable for the 424 determination of electrical resistivity contrasts of resistive features.

425 Although interpretations of both electrical conductivity and magnetic susceptibility 426 measurements are presented in this study, it is important to note that contrary to the electrical 427 resistivity which most often belongs to the $[1,10,000 \Omega \mathrm{m}]$ interval, the range of relative 428 magnetic permeability values is very narrow: between 1.00 and 1.01 . Consequently it is 429 sufficiently small for the 'magnetic' EMI responses to be considered as linear. This means 430 that a wide range of linear techniques, such as linear filtering, can be applied to the 431 interpretation of apparent magnetic susceptibility maps. Further research is needed, to 432 evaluate potential developments and applications for these techniques. 


\section{References}

436 Auken E. and A. V. Christiansen, 2004, Layered and laterally constrained 2D inversion of 437 resistivity data: Geophysics, $\mathbf{6 9}, 752-761$.

Bendjoudi H., P. Weng, R. Guérin and J. F. Pastre, 2002, Riparian wetlands of the middle search of the Seine river (France): historical development, investigation and present hydrologic functioning: Journal of Hydrology, 263, 131-155.

Benech C., 2000, Interprétation conjointe de cartographies magnétique et électromagnétique

442 des propriétés magnétiques des sols anthropisés. Thèse Université Pierre et Marie Curie, 443 Paris.

444 Benech C., A. Tabbagh and G. Desvignes, 2002, Joint interpretation of E. M. and magnetic 445 data for near-surface studies: Geophysics, 67, 1729-1739.

446 Brinon C., F.-X. Simon, and A. Tabbagh, 2012, Rapid 1D/3D inversion of shallow resistivity 447 multipole data: examples in archaeological prospection: Geophysics, 77, no. 3, E193-E201.

448 Bonsall J., R. Fry, C. Gaffney, I. Armit, A. Beck and V. Gaffney, 2013, Assessment of the 449 CMD mini-explorer, a new low-frequency multi-coil electromagnetic device, for 450 archaeological investigations: Archaeological Prospection, 20, 219-231.

451 Dabas M., A. Anest, J. Thiesson and A. Tabbagh, 2015, Slingram EMI devices for 452 characterizing resistive features using apparent conductivity measurements: check of the 453 DualEM-421S instrument and field tests: Submitted to Archaeological Prospection.

454 De Jong E., A. K. Ballantyne, D. R. Cameron and D. W. L. Read, 1979, Measurement of 455 apparent electrical conductivity of soil by an electromagnetic induction probe to aid salinity 456 surveys: Soil Science Society of America Journal, 43, 810-812.

457 DualEM-421S User's manual, 2010, Milton, Ontario, Canada, 32p. 
Farquharson C. G., D. W. Oldenburg and P. S. Routh, 2003, Simultaneous 1D inversion of

459 loop-loop electromagnetic data for magnetic susceptibility and electrical conductivity:

460 Geophysics: 68, 1857-1869.

461 Flageul S., M. Dabas, J. Thiesson, F. Réjiba and A. Tabbagh, 2013, First in situ tests of a new

462 electrostatic resistivity meter: Near Surface Geophysics, 11, 265-273.

463 Guérin R., Y. Méhéni, G. Rakontodrasoa and A. Tabbagh, 1996, Interpretation of Slingram

464 conductivity mapping in near surface geophysics: using a single parameter fitting with 1D

465 model: Geophysical Prospecting, 44, 233-249.

466 Guyard L. and T. Lepert, 1999, Le Vieil- Evreux, ville sanctuaire gallo-romaine : Archeologia

$467359,20-29$.

468 Hesse A., 1987, Balloy 1986-1987. Rapport de synthèse sur les prospections géophysiques

469 des vestiges archéologiques : Direction régionale des antiquités d'Ile de France, août 1987, $47015 \mathrm{p}$.

471 Hoefer G., J. Bachmann and K. H. Hartge, 2010, Can EM38 probe detect spatial pattern of 472 subsoil compaction?, In Proximal Soil Sensing, Progress in Soil Science 1, R.A. Viscarra 473 Rossel et al. (eds.), Chapter 22, 265-273.

474 Hohmann G. W., 1975, Three dimensional induced polarization and electromagnetic 475 modeling: Geophysics, 40, 309-320.

476 Huang H. and D. C. Fraser, 1996, The differential parameter method for multi-frequency 477 airborne resistivity mapping: Geophysics, 61, 100-109.

478 Huang H. and D. C. Fraser, 2002, Dielectric permittivity and resistivity mapping using high 479 frequency, helicopter born EM data: Geophysics, 67, 727-738.

480 Kacahnoski R. G., E. G. Gregorich and I. J. van Wesenbeek, 1988, Estimating spatial 481 variations of soil water content using non-contacting electromagnetic inductive methods: 482 Canadian Journal of Soil Science, 68, 715-722. 
Marquardt, D. W., 1963, An algorithm for least square estimation of nonlinear parameters: Journal of the Society for Industrial and Applied Mathematics, 11, 431-441.

McNeill J. D., 1980, Electromagnetic terrain conductivity measurement at low induction numbers: Geonics Limited Technical Notes, TN-6, 15p.

Mordant D., 1997, Le complexe des Réaudins à Balloy: enceinte et nécropole monumentale. La Culture de Cerny. Nouvelle économie, nouvelle société au Néolithique: Actes du Colloque International de Nemours 1994, Mémoires du Musée de Préhistoire d'Ile-de-France, 6, 449-479.

Parchas C. and A. Tabbagh; 1978, Simultaneous measurement of electrical conductivity and magnetic susceptibility of ground in electromagnetic prospecting: Archaeo-Physika, 10, 682691

Raiche A. P., 1974, An integral equation approach to three dimensional modelling: Geophysical Journal of the Royal Astronomical Society, 36, 363-376.

Saey T., P. De Smedt, E. Meerschman, M.-M. Islam, F. Meeuws, E. van De Vijver, A. Lehouck and M. van Meirvenne, 2012, Electrical conductivity depth modelling with a multireceiver EMI sensor for prospecting archaeological features: Archaeological Prospection, 19, 21-30.

Santos, F. M., 2004, 1-D laterally constrained inversion of EM34 profiling data: Journal of Applied Geophysics, 56, 123-134.

Scollar I., A. Tabbagh, A. Hesseand I. Herzog, 1990, Archaeological prospection and remote sensing. Cambridge University Press, 674p.

Tabbagh A., 1985, The response of a tree dimensional magnetic and conductive body in shallow depth EM prospecting: Geophysical Journal of the Royal Astronomical Society, 81, 215-230. 
507 Tabbagh A., 1986, What is the best coil orientation in the slingram electromagnetic 508 prospecting method? Archaeometry, 28, 185-196.

509 Thiesson J, M. Dabas and S. Flageul, 2009, Detection of resistive features using towed

510 Slingram electromagnetic induction instruments: Archaeological Prospection, 16: 103-109.

511 Tite M. S. and C. E. Mullins, 1970, Electromagnetic prospecting on archaeological sites using 512 a soil conductivity meter: Archaeometry, 12, 97-106.

513 Vitharana U. W. A., M. van Meirvenne, D. Simpson, L. Cockx and G. Hofman, 2008, 514 Agronomic consequences of potential zones delineated on the basis of EM38DD 515 measurements: Near Surface Geophysics, 6, 289-296. 


\section{Figure captions}

Figure 1: Synthetic data for three different Slingram devices, recorded above an elongated, 3D body (resistivity $=20 \Omega \mathrm{m}$, susceptibility $=80 \times 10^{-5} \mathrm{SI}$ ) of dimensions: length=3 $\mathrm{m}$, width $=1 \mathrm{~m}$, thickness $=1 \mathrm{~m}$, embedded in the second layer of a three layer ground, the top of which is located $0.3 \mathrm{~m}$ below the ground surface (first layer $100 \Omega \mathrm{m}, 30 \times 10^{-5} \mathrm{SI}$ and $0.2 \mathrm{~m}$, second layer $200 \Omega \mathrm{m}, 20 \times 10^{-5} \mathrm{SI}$ and $2 \mathrm{~m}$, third layer $50 \Omega \mathrm{m}$ and $\left.10 \times 10^{-5} \mathrm{SI}\right)$. The rectangular dotted line indicates the contours of the targeted area used for 3D interpretation

(a) Apparent resistivity maps for in-line

(b) Apparent magnetic susceptibility maps for in-line measurements, and vertical section of the feature.

Figure 2: Apparent magnetic susceptibility maps of the artificial L-shaped feature at the Garchy site and first and second layer susceptibility variations after 1D inversion. The two dashed rectangles indicate the contours of the two targeted areas used for 3D inversion.

Figure 3: Apparent resistivity maps of the artificial L-shaped feature at the Garchy site and second layer resistivity variations after 1D inversion

Figure 4: Apparent resistivity maps of the Fanum area at Vieil-Evreux, corresponding to quadrature measurements using DualEM HCP 1m, HCP 2m, PERP1.1m and PERP2.1m configurations. The rectangles indicate the contour of the targeted area on which 3D interpretation is applied.

Figure 5: Apparent magnetic susceptibility map of the Neolithic funeral enclosure at Balloy (Seine et Marne, France), using in-phase SH3 measurements. The rectangles indicate the contour of the targeted area used for 3D inversion. 


\section{Table captions}

544 Table 1: Numerical values obtained after 3D inversion of synthetic data. First four columns:

545 resistivity, conductivity and vertical extent of the body and relative RMS error, based on 546 apparent resistivity data inversion. Last three columns: magnetic susceptibility, vertical extent 547 of the body, and relative RMS error based on apparent magnetic susceptibility inversion. The 548 definition of the relative RMS error is the

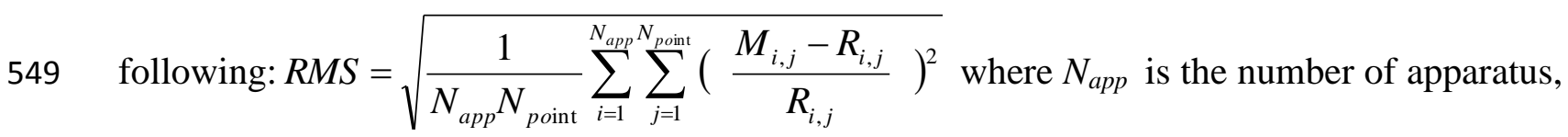
$N_{\text {point }}$ the number of points, $M_{i, j}$ the measurement with the $i$ apparatus at the point $j$ and $R_{i, j}$ the 551 theoretical measurement with the $i$ apparatus at point $j$.

552

Table 2: Electrical conductivity and magnetic susceptibility contrasts and inversion relative RMS error obtained from 3D inversion, using each instrument separately, and using both instruments together. The starting a priori values adopted for conductivity are indicated in parentheses.

557

558 Table 3: Conductivity contrasts and inversion relative RMS error obtained between the external fanum wall and the surrounding layer (the wall has a $1.00 \times 0.88 \mathrm{~m}^{2}$ section and is centred at $0.70 \mathrm{~m}$ depth). The starting a priori values adopted for conductivity are also 561 indicated. 


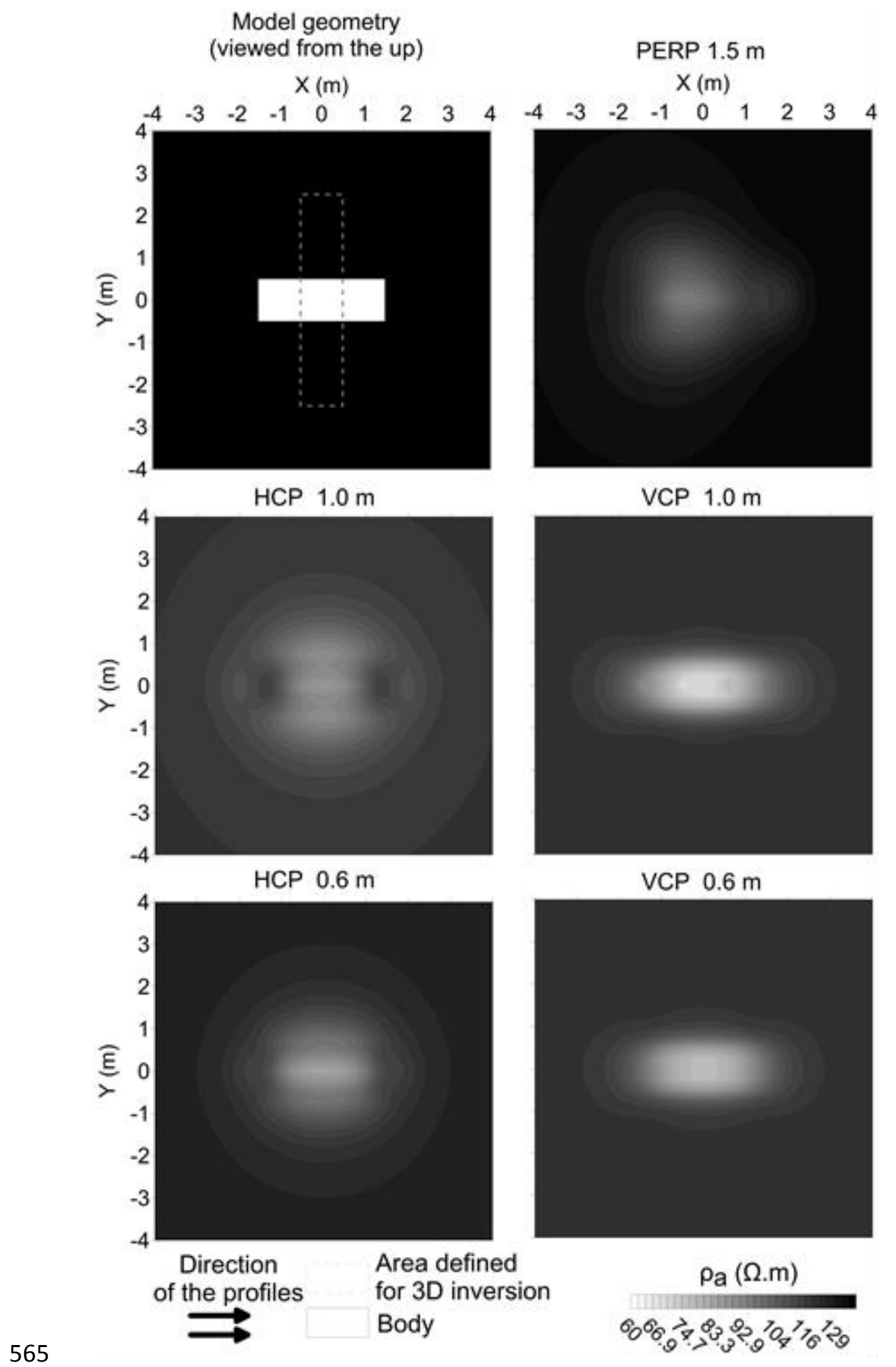

566 Fig. 1a 


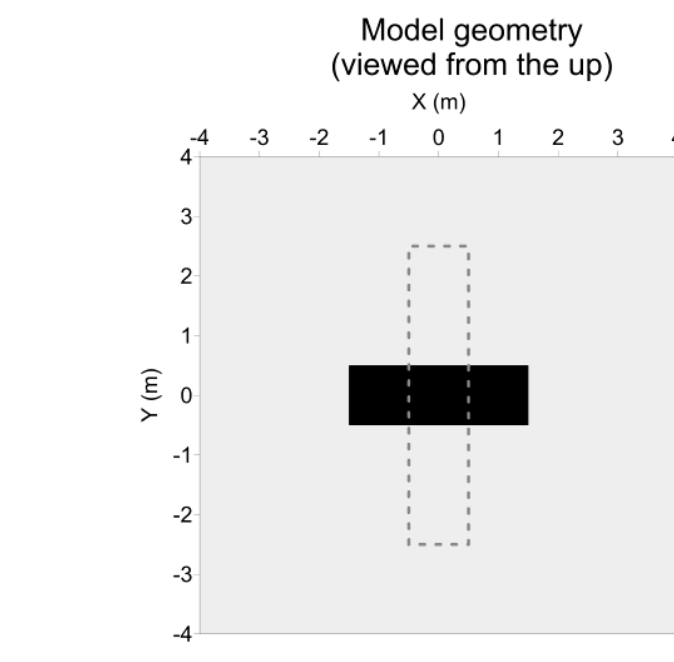

Model geometry (viewed from the side)
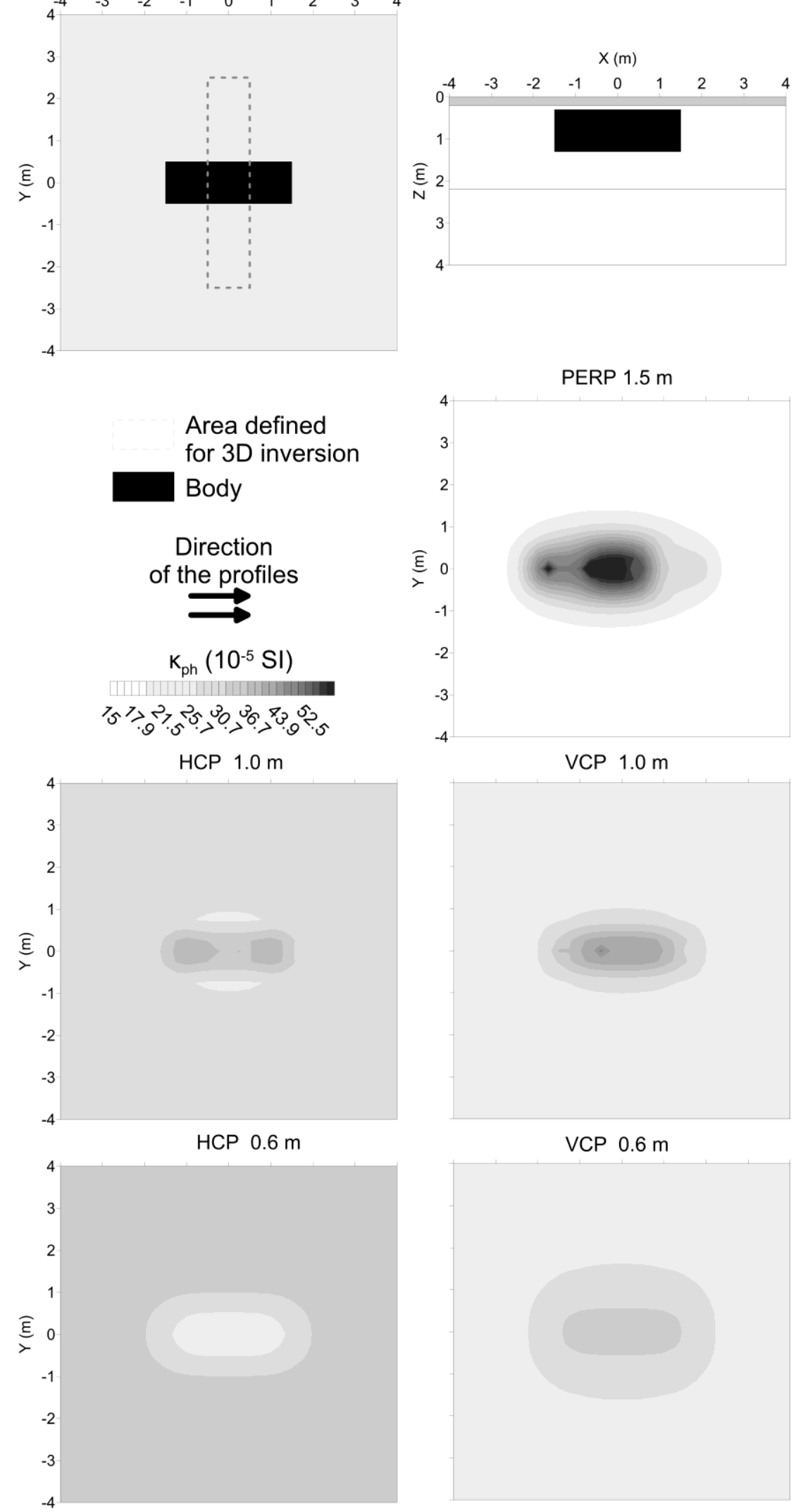

Fig. 1b 


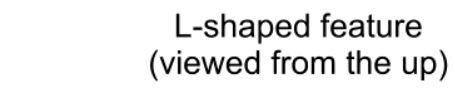

$X(\mathrm{~m})$
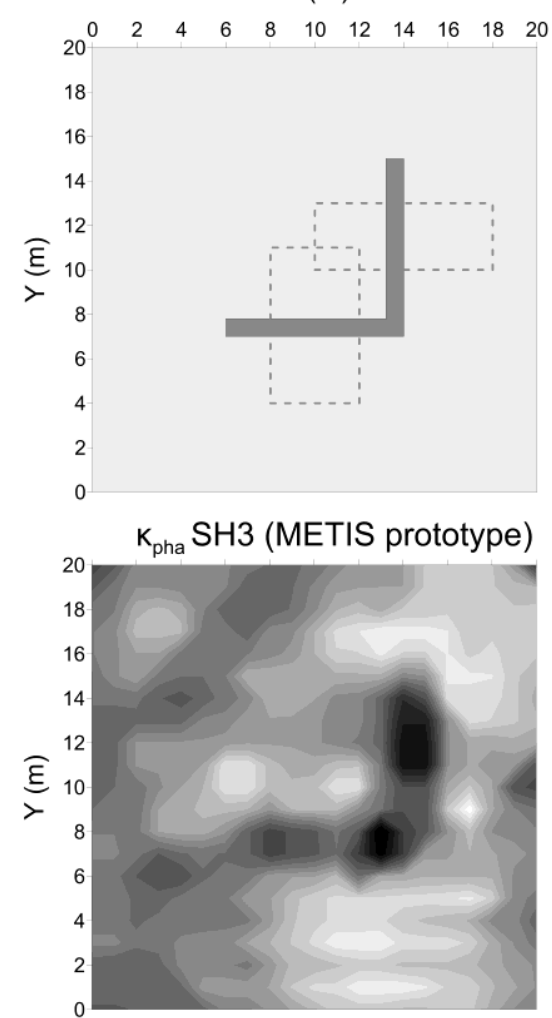

Direction of the profiles

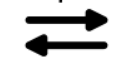

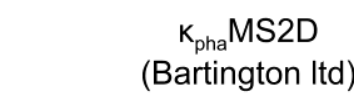

$X(\mathrm{~m})$

$\begin{array}{lllllllllll}0 & 2 & 4 & 6 & 8 & 10 & 12 & 14 & 16 & 18 & 20\end{array}$

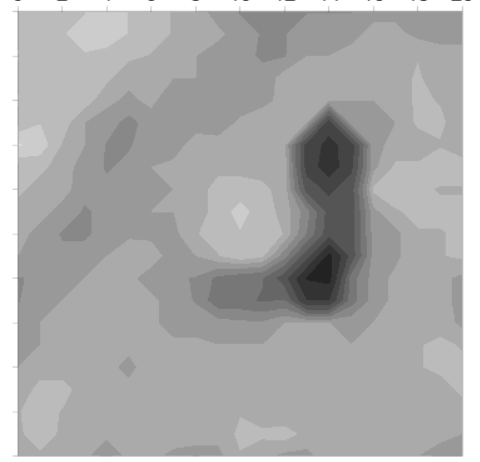

$\mathrm{K}_{\text {pha }}$ EM38 VCP (Geonics)

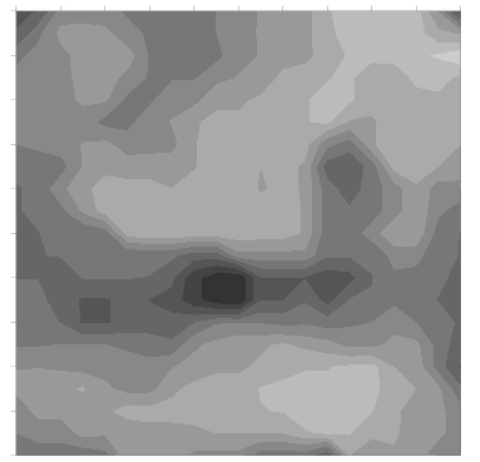

Area defined for 3D inversion

$\mathrm{L}$ shaped trench

$$
\mathrm{K}_{\mathrm{ph}}\left(1^{\text {st }} \text { layer }\right)
$$

$\mathrm{X}(\mathrm{m})$

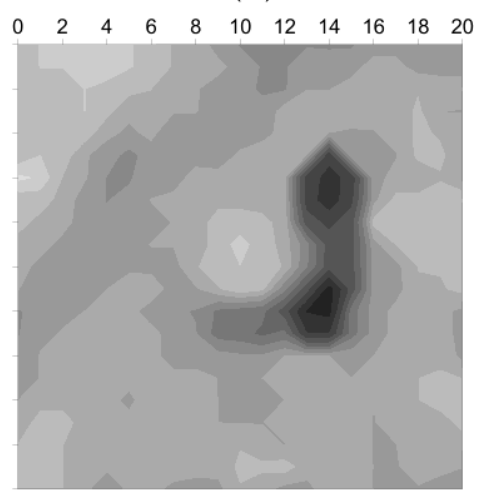

$\mathrm{K}_{\mathrm{ph}}\left(2^{\text {nd }}\right.$ layer $)$

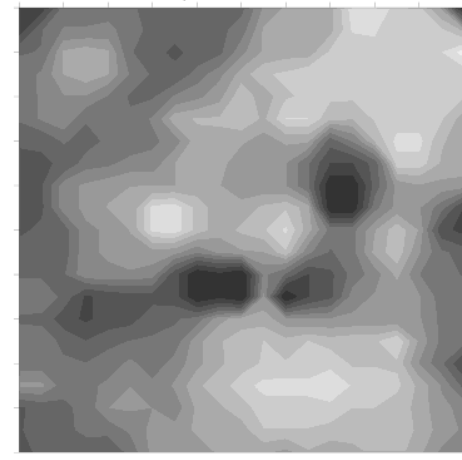

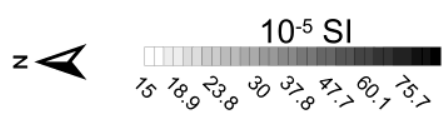

\section{$571 \quad$ Fig. 2}




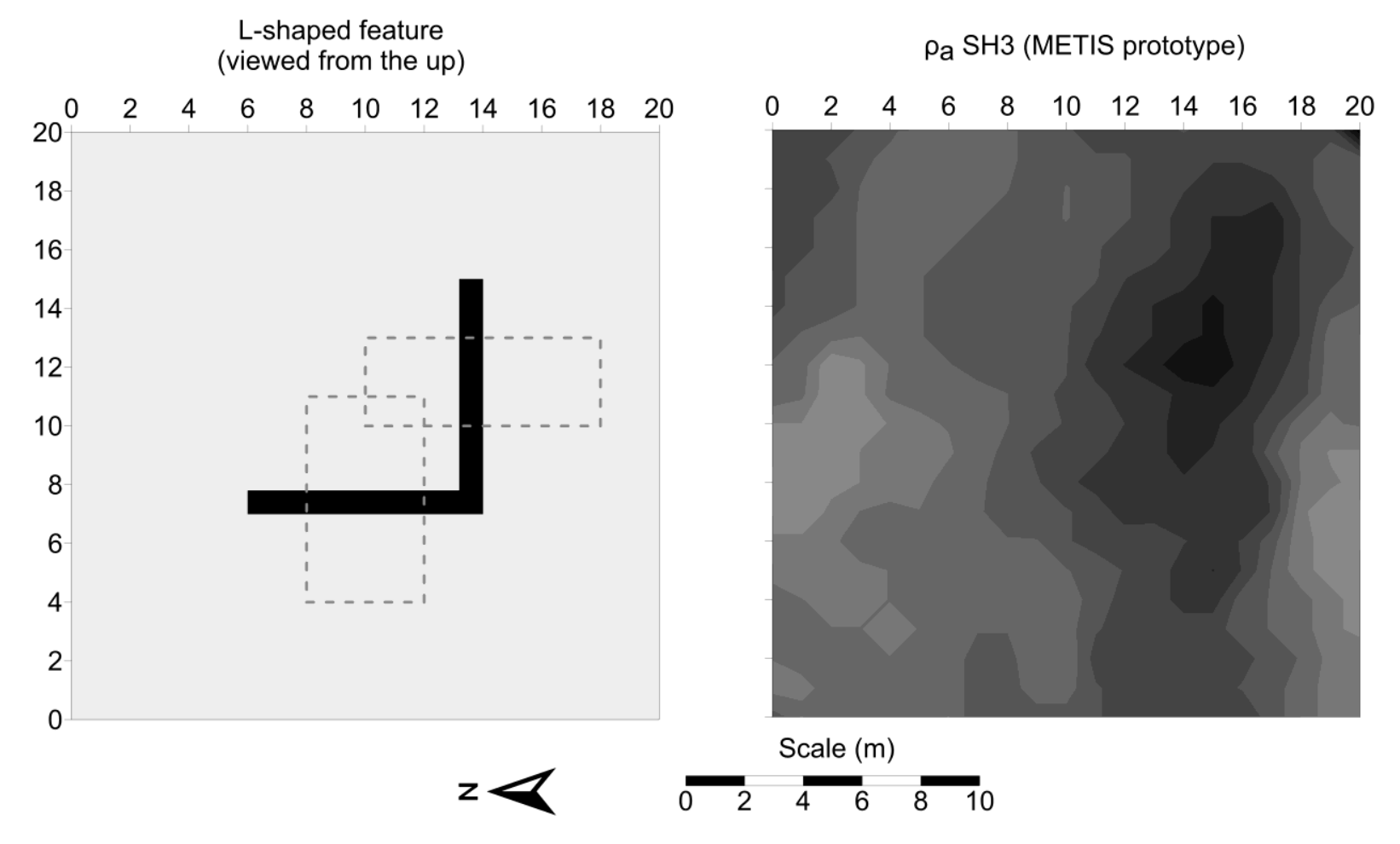

Pa SH3 (METIS prototype)

$\rho_{a}$ EM38 VCP (Geonics)

$\rho\left(2^{\text {nd }}\right.$ layer $)$
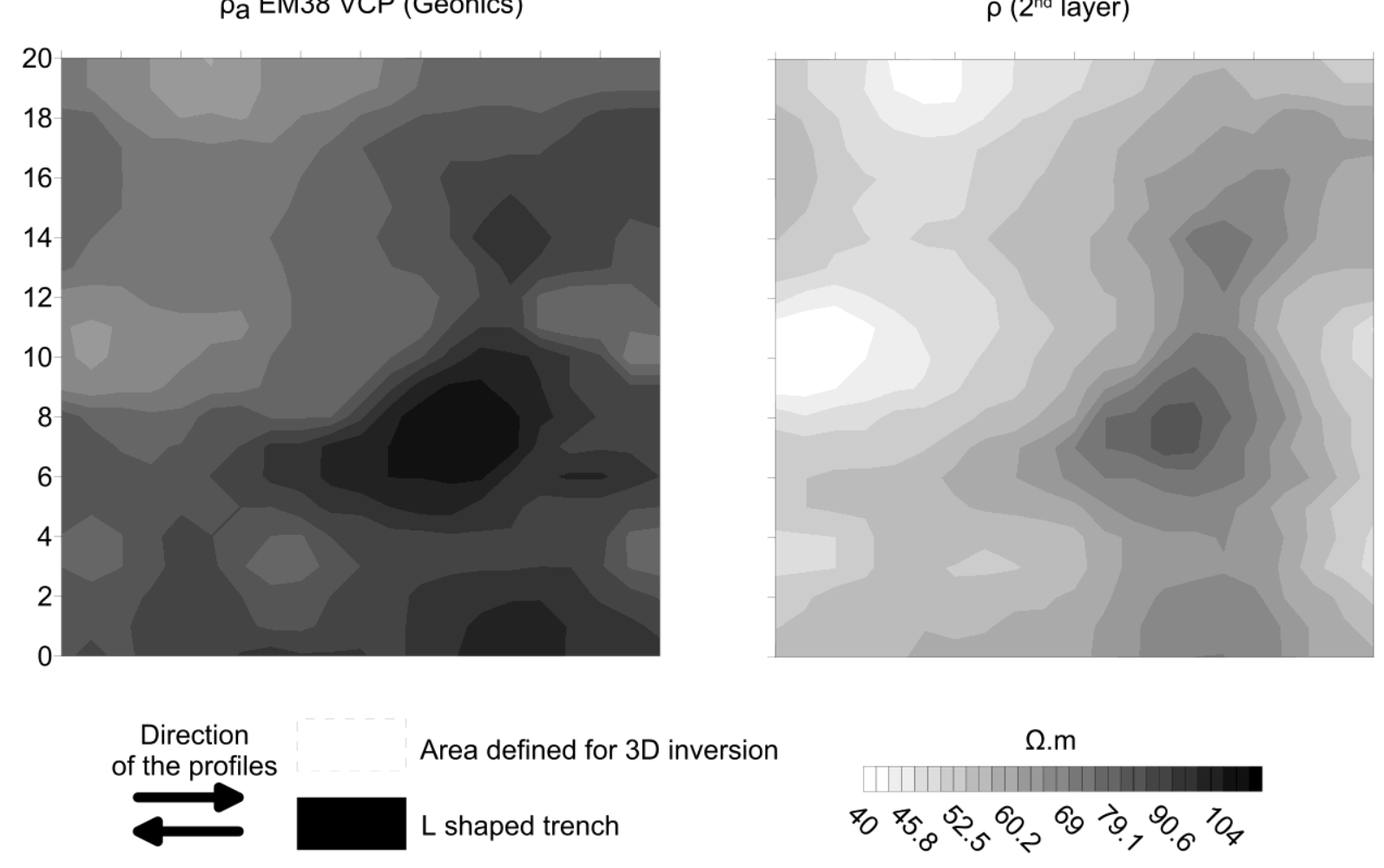

L shaped trench

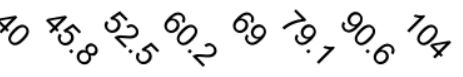

$575 \quad$ Fig. 3 


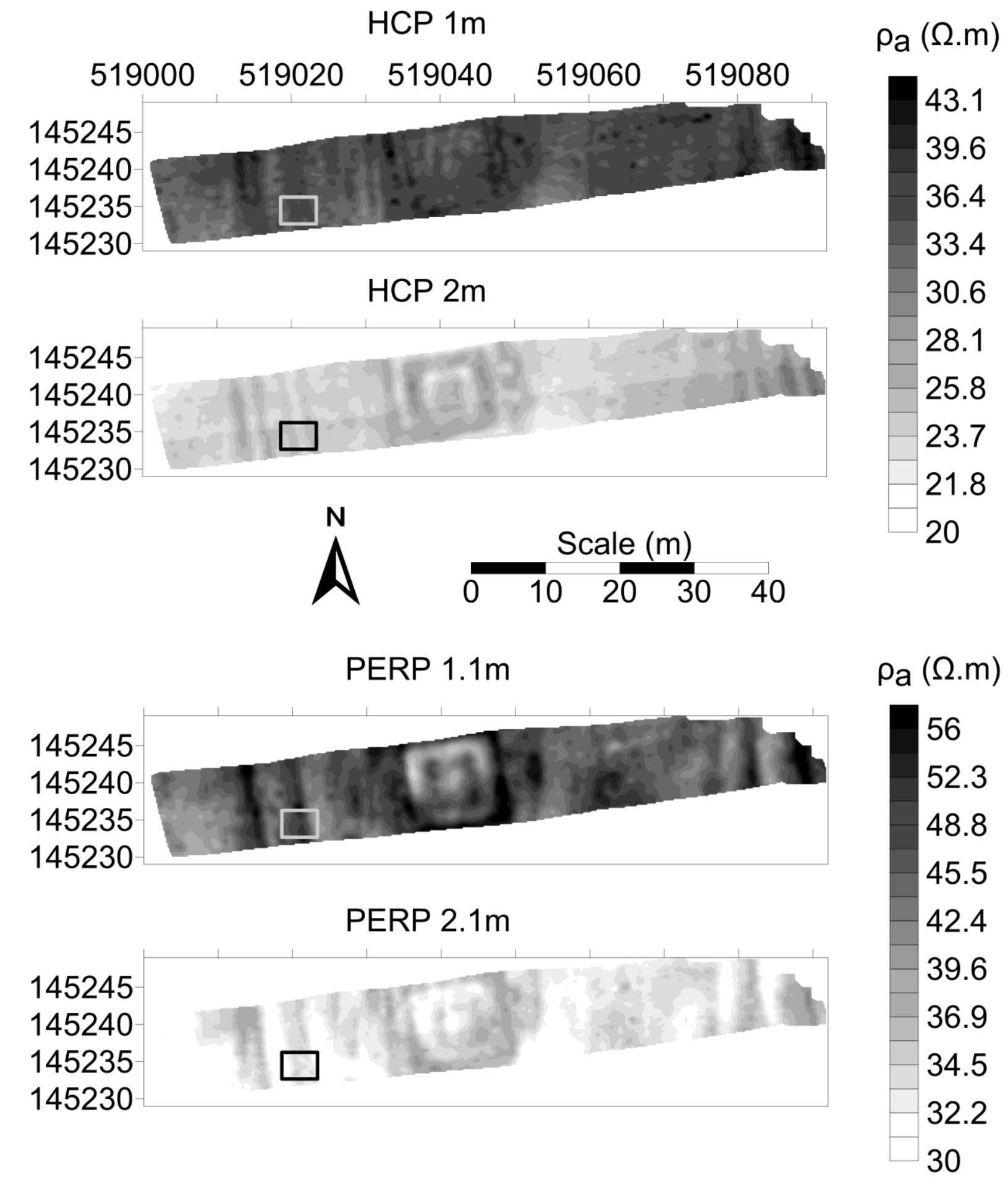

$578 \quad$ Fig. 4 


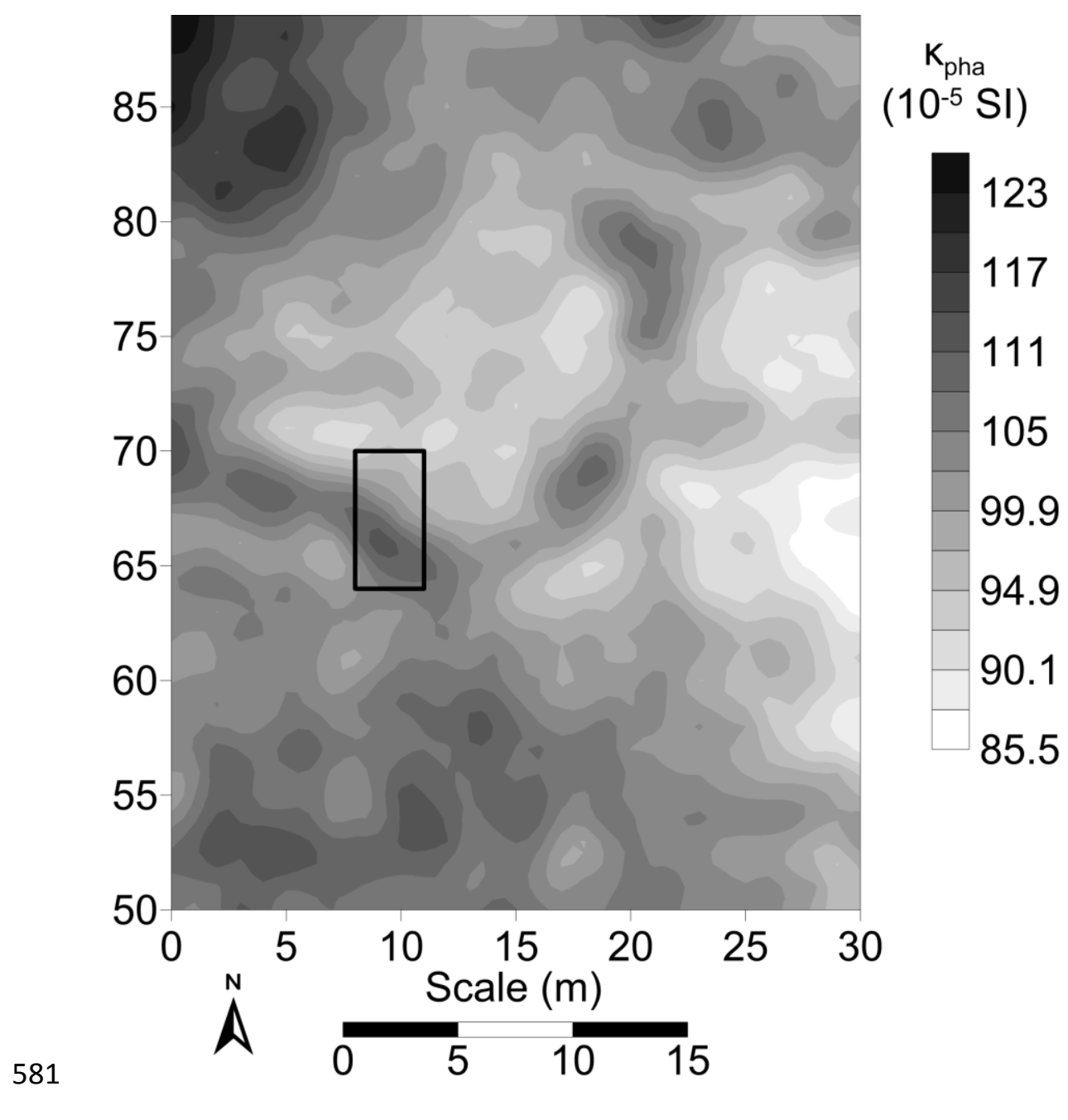

$582 \quad$ Fig. 5

583 


\begin{tabular}{|c|c|c|c|c|c|c|c|c|}
\hline & $\begin{array}{c}\rho_{\mathrm{b}} \\
(20 \Omega \mathrm{m})\end{array}$ & $\begin{array}{c}\sigma_{\mathrm{b}} \\
(50 \\
\left.\mathrm{mSm}^{-1}\right)\end{array}$ & $\begin{array}{l}\mathrm{Zl} \\
(1 \mathrm{~m}) \\
\text { Using the } \\
\text { resistivity } \\
\text { map }\end{array}$ & $\begin{array}{c}\text { Relative } \\
\text { RMS } \\
\text { error }\end{array}$ & $\begin{array}{c}\kappa_{\mathrm{b}} \\
\left(8010^{-5}\right. \\
\mathrm{SI})\end{array}$ & $\begin{array}{c}\text { Zl } \\
(1 \mathrm{~m}) \\
\text { Using the } \\
\text { susceptibility } \\
\text { map }\end{array}$ & $\begin{array}{c}\text { Relative } \\
\text { RMS } \\
\text { error }\end{array}$ & $\begin{array}{c}\kappa_{\mathrm{b}} \\
\left(8010^{-5}\right. \\
\mathrm{SI})\end{array}$ \\
\hline VCP $0.6 \mathrm{~m}$ & 20.9 & 47.8 & 0.84 & 0.028 & 76.5 & 0.98 & 0.030 & 76.5 \\
\hline HCP $0.6 \mathrm{~m}$ & 22.3 & 44.8 & 0.82 & 0.021 & 77.5 & 0.95 & 0.094 & 77.5 \\
\hline VCP $1 \mathrm{~m}$ & 19.4 & 51.5 & 0.85 & 0.038 & 80.1 & 1.00 & 0.031 & 80.1 \\
\hline $\mathrm{HCP} 1 \mathrm{~m}$ & 22.9 & 43.7 & 0.80 & 0.034 & 66.8 & 0.96 & 0.056 & 66.8 \\
\hline PERP $1.5 \mathrm{~m}$ & 23.5 & 42.6 & 0.81 & 0.043 & 81.3 & 1.02 & 0.059 & 81.3 \\
\hline $\begin{array}{c}5 \\
\text { configurations }\end{array}$ & 21.4 & 46.7 & 0.82 & 0.039 & 79.8 & 0.98 & 0.036 & 79.8 \\
\hline
\end{tabular}

Table 1

\begin{tabular}{|c|c|c|c|c|}
\hline & N-S Branch & & E-W Branch & \\
\hline & $\begin{array}{l}\text { Electrical conductivity } \\
\text { contrast (in } \mathrm{mSm}^{-1} \text { ) with } \\
\text { starting a priori value }\end{array}$ & $\begin{array}{l}\text { Relative } \\
\text { RMS error }\end{array}$ & $\begin{array}{l}\text { Electrical conductivity } \\
\text { contrast (in } \mathrm{mSm}^{-1} \text { ) with } \\
\text { starting a priori value }\end{array}$ & $\begin{array}{l}\text { Relative } \\
\text { RMS error }\end{array}$ \\
\hline $\begin{array}{l}\text { EM38-VCP } \\
\text { (Quadrature) }\end{array}$ & $\begin{array}{c}-10.0 \\
\text { (a priori at }-6.2 \text { ) }\end{array}$ & 0.126 & $\begin{array}{c}-13.9 \\
\text { (a priori at }-6.2 \text { ) }\end{array}$ & 0.071 \\
\hline $\begin{array}{c}\text { SH3 } \\
\text { (Quadrature) }\end{array}$ & $\begin{array}{c}0.0 \\
\text { (a priori at -14.9) }\end{array}$ & 0.058 & $\begin{array}{c}1.75 \\
\text { (a priori at -12.0) }\end{array}$ & 0.092 \\
\hline \multirow[t]{2}{*}{$\begin{array}{c}\text { EM38-VCP \& SH3 } \\
\text { (Quadrature) }\end{array}$} & $\begin{array}{c}-8.4 \\
\text { (a priori at }-9.0 \text { ) }\end{array}$ & 0.102 & $\begin{array}{c}-9.6 \\
\text { (a priori at }-8.6 \text { ) }\end{array}$ & 0.097 \\
\hline & $\begin{array}{l}\text { Magnetic susceptibility } \\
\text { contrast (in } 10^{-5} \mathrm{SI} \text { ) }\end{array}$ & & $\begin{array}{c}\text { Magnetic susceptibility } \\
\text { contrast }\left(\text { in } 10^{-5} \mathrm{SI}\right)\end{array}$ & \\
\hline $\begin{array}{l}\text { EM38-VCP } \\
\text { (in-Phase) }\end{array}$ & 64.5 & 0.076 & 50.5 & 0.170 \\
\hline $\begin{array}{c}\text { SH3 } \\
\text { (in-Phase) }\end{array}$ & 39.5 & 0.140 & 108.5 & 0.150 \\
\hline $\begin{array}{c}\text { EM38-VCP \& SH3 } \\
\text { (in-Phase) }\end{array}$ & 47.4 & 0.077 & 109.7 & 0.084 \\
\hline
\end{tabular}

Table 2

590 


\begin{tabular}{|c|c|c|c|}
\hline & $\begin{array}{c}\text { Conductivity contrast } \\
\text { starting a priori values } \\
{\text { (in } \mathrm{mSm}^{-1}}\end{array}$ & $\begin{array}{c}\text { Inverted conductivity contrast } \\
\left(\text { in } \mathrm{mSm}^{-1} \text { ) }\right.\end{array}$ & $\begin{array}{c}\text { Relative } \\
\text { RMS error }\end{array}$ \\
\hline HCP 1m + HCP 2m + & -23.3 & -0.32 & 0.021 \\
\hline PERP 1.1m +PERP 2.1m & -28.5 & +10.5 & 0.003 \\
\hline HCP 1m & -30.8 & -3.5 & 0.002 \\
\hline HCP 2m & -28.5 & -8.0 & 0.005 \\
\hline PERP 1.1m & -28.5 & 0.34 & 0.002 \\
\hline
\end{tabular}

Table 3 